\title{
Portrayal of Violence against Women Rights in Pashtun and Punjab Community: A Comparative Analysis of Daily Express Peshawar and Lahore Edition
}

\author{
Khayam Hassan*, Dr. Sajjad Ali**, Dr. Faiza Latif***
}

\begin{abstract}
The aim of this study was to find out the social construction of reality of media regarding women rights' violation in Pashtuns and Punjabis communities in print media, for which Urdu daily Express was selected. The researchers collected data from the newspaper's Peshawar and Lahore editions from January to March, 2015. For the data collection, the researchers used coding sheet which was devolved under the consideration of objective and research hypotheses. Data was collected through purposive sampling methodology. The results of the study explored that both the editions of the daily Express covered the issues of women rights' violation. It also disclosed that Peshawar edition has given more coverage on the front, city and back pages to women rights violation than the Lahore edition. The results disclosed that the Lahore edition has not ethically covered news about women rights' violation, while the Peshawar edition covered it more ethically. It is concluded that Peshawar-based journalists are following cultural values of Pashtun society, that is why the issue has been covered positively in the area.
\end{abstract}

Keywords: Portrayal, women rights violation, print media, Pashtuns community, Punjabis community.

This Article can be cited as:

Hassan K., Ali S., Latif F., (2020). Portrayal of Violence against Women Rights in Pashtun and Punjab Community: A Comparative Analysis of Daily Express Peshawar and Lahore Edition, Journal of Arts and Social Sciences. VII (1), 67-74.

\footnotetext{
* Khayam Hassan, Visiting Lecturer, Department of Media \& Communication Studies, University of Swat, Khyber Pakhtunkhwa.

** Correspondence concerning this article should be addressed to Dr. Sajjad Ali, Assistant Professor, Department of Journalism and Mass Communication, University of Malakand, Khyber Pakhtunkhwa, sajjadjmc.uop@gmail.com

*** Dr. Faiza Latif, Assistant Professor, Department of Mass Communication, Lahore College for Women University, Lahore.
} 


\section{Introduction}

Media is playing a vital role in the improvement, violation and reproduction of a culture and a particular community, because media is called the mirror of the society. It is fact that when a society expose bad in the face of media, the readers, listeners and viewers will get the inspiration as media expose. In the current study the researchers aim to find out the social reality and social responsibility of the Pakistani media. The researchers compared two mainstream community presentations in the print media particularly in Urdu newspapers of Pakistan. In the present situation of Pakistan two mainstream communities Punjabi and Pathan (Pashtuns) blaming each other due to un-factual and un-evidential myths. Every community show dominancy on each other, such as Punjabi community says that Pathans are cruel and violating women rights, while Punjabi is not performing the same practice. As like the Pathan also are blaming on Punjabis' that they are violating the women rights. This study also provided guideline for the media and particularly for print media to present the social reality of the society as it is considered the mirror of the society.

\section{Statement of the Problem}

It is verity that Pathans and Punjabi doing the violation of women rights with different ways but who is doing more it is a confusing phenomenon. Women rights violations is the main hurdle in the way of women empowerment as Pakistani communities such as Punjabis, Pashtuns, Sindhi and Balochies are violating their rights with different ways (Mubarak, Rana, Khan, Mujahid, \& Chawla, 2020). Under the consideration of this fact the researcher conducted this study to investigate the women rights violation among the both communities to explore the reality.

\section{Objectives of the Study}

The main objective of the study was to find out the presentation of women right violation in Print media of Pakistan. The specific objectives are;

- To evaluate the news contents of daily Express Peshawar and Lahore edition about women violence.

- To search out the coverage of issues about women violence.

- To compare the coverage and presentation of selected editions of a newspaper.

- To compare the women right violation in the Punjab and Pashtun communities.

- To compare the issues of women's right highlighted in the selected editions newspaper.

\section{Hypotheses}

$\mathrm{H}_{1}$. Violation of women rights is greater in Punjab community than the Pashtuns.

$\mathrm{H}_{2}$. Coverage of women related crime issues are more in Peshawar edition than Lahore edition.

$\mathrm{H}_{3}$. Peshawar edition is more ethical in covering issues of women rights violation.

$\mathrm{H}_{4}$. Lahore edition newspaper gives more importance to issues related to women rights violation.

\section{Review of Literature}

Hassan. Taimur-Ul (2012) analyzed the Pakistani newspapers role in the regarding civil society in the context of social responsibility. The researcher did content analysis of the Urdu and English mainstream newspapers from 2000 to 2003 through purposive sampling. He exposed that Pakistani newspapers are giving space to the civil society problems. He said that particularly the newspapers presented the women right violation such as honor killing and crime against women on daily bases. He said that this responsibility not only improve the credibility of the press but also performing social responsibility. 
Naylor (2001), said that social problems highlighting the media and the print media particularly. He disclosed that idea after conducting research on the British media. He said news stories about women right violation and crime is only to sell the newspaper circulation in the country. He also said while the other side didn't perform the social responsibility that what will be effect of this type of stories on the new generation.

Tasneem Ahmar (2001) studied that overall country print journalism coverage regarding women in the time period of 2000-2001. She used the data from the all four provinces of the country with collaboration of coordinators in respective provinces. They analyze all the data of the Urdu and English newspapers and find out that the role of print regarding women issue is not effective, because the presentation, language, placement and interpretation didn't suitable according to women laws, ethics and Islamic perspective.

Jawed Syed (2008) investigates the role of print media in ethnicity, race and religion. The author aims to investigate that how the Pakistani media present the ideologies in the news contents? For this purpose, he analyzed the mainstream Urdu Newspapers Jang and Nawa-i-waqt from February to July 2006. He found that the print media of Pakistan remain ignored the sub-culture, race and religion. Which show the subjective of the print media of Pakistan. He said that it is responsibility of the press to cover all the ethnicity, race and religion practice in positive approach to bring equability in the society.

\section{Theoretical Framework}

Ruben David. H (1997) said that the Social Construction of Reality theory was presented in 1995. He explained that this theory basically explored the linguistics realities on the base of reality, but he also argued that the sources of communication are the main factors to construct social reality such as media role in the society.

This theory is related to the current study as media playing a vital role for construction of social reality, means that media show the reality of the society to the public. So the researcher selected this theory to verify the assumption of the theory in light of print media presentation regarding the social issues in the country particularly towards women rights violation.

\section{Research Design}

Wimmer and Dominic (2011) said that scientific research is an organized, objective, controlled, qualitative or quantitative empirical analysis of one or more variables.

The researchers conducted this research on the base of quantitative research methodology to evaluate the phenomena, while, data was collected from the mainstream Urdu Newspaper Daily Express Peshawar Edition and Daily Express Lahore Edition; from January, 2015 to March, 2015 as purposive sampling technique through contents analysis to examine the problem. The Express Urdu newspaper was started on September, 3, 1998 by Lakson Group. Coding sheet was used as data collection tool, whereas, Statistical Package for Social Sciences (SPSS, version, 19) for the data analysis to ensure objectivity in the results.

\section{Results}

Table 1. Stories distribution of the women rights violation news in express Peshawar \& Lahore edition

\begin{tabular}{llllll}
\hline Variables & F & \% & Variables & F & \% \\
Peshawar & 39 & 50.6 & Pashtun & 39 & 50.6 \\
edition & & & & & \\
Lahore edition & 38 & 49.4 & Punjabi & 38 & 49.4 \\
Total & 77 & 100.0 & Total & 77 & 100.0 \\
\hline
\end{tabular}


Peshawar edition covered more stories than Lahore edition as show table 1 that $50.6 \%$ stories have been published by Peshawar edition, while $49.4 \%$ by Lahore edition regarding women rights violation. The table also illustrates the community coverage which is similar to the coverage of stories.

Table 2. Page wise distribution of the women rights violation news in express Peshawar \& Lahore edition

\begin{tabular}{llllll}
\hline Peshawar & & & Lahore & & \\
Variables & F & $\%$ & Variables & $\mathbf{F}$ & $\%$ \\
Front page & 7 & 17.9 & Front page & 4 & 10.5 \\
City page & 3 & 7.7 & City page & 11 & 28.9 \\
Back page & 29 & 74.4 & Back page & 23 & 60.5 \\
Total & 39 & 100.0 & Total & 38 & 100.0 \\
\hline
\end{tabular}

Table 2 exemplify the distribution of the women rights violation news that Peshawar edition covered more news stories $74.4 \%$ on back page, $7.7 \%$ on city page and $17.9 \%$ on front page. On the other side Lahore edition published also more news $60.5 \%$ on back page, $28.9 \%$ on city page, whereas, $10.5 \%$ on front pages. It is inferred that Peshawar edition has been given more coverage on front and back pages as compare to Lahore edition.

Table 3. Column wise distribution of the women rights violation news in express Peshawar \& Lahore edition

\begin{tabular}{llllll}
\hline Peshawar & & & Lahore & & \\
Variables & $\mathbf{F}$ & $\mathbf{\%}$ & Variables & $\mathbf{F}$ & $\mathbf{\%}$ \\
$1-2$ columns & 38 & 97.4 & $1-2$ columns & 31 & 82 \\
$3-4$ columns & 1 & 2.6 & $3-4$ columns & 7 & 18 \\
Total & 39 & 100.0 & Total & 38 & 100.0 \\
\hline
\end{tabular}

Column wise distribution shown in the Table 3 that due to the burning issue Peshawar edition covered $97.4 \%$ news stories 1 to 2 columns and 2.6\% 3 to 4 columns, while Lahore edition published $82 \%$ 1 to 2 columns and $18 \% 3$ to 4 columns. It is concluded that Peshawar edition given more coverage to women rights violation than Lahore edition.

Table 4. Ethical representation of the women rights violation news in express Peshawar \& Lahore edition

\begin{tabular}{llllll}
\hline Peshawar & & & Lahore & & \\
Variables & F & \% & Variables & F & \% \\
Ethical & 37 & 94.9 & Ethical & 36 & 94.7 \\
Unethical & 2 & 5.1 & unethical & 2 & 5.3 \\
Total & 39 & 100.0 & Total & 38 & 100.0 \\
\hline
\end{tabular}

To find out ethical standards of the newspaper regarding the violation of women rights issues Table 4 illustrates that $94.9 \%$ news stories have followed journalistic ethics, while only $5.1 \%$ unethically reported by Peshawar edition. On the other hand, Lahore based reporters followed $94.7 \%$ ethical standards, while 5.3\% stories were filed unethically. It is shows that Peshawar based reporters followed ethics more than Lahore base reporters during filing stories regarding women rights violation.

Table 5. Pictorial representation of the women rights violation news in express Peshawar \& Lahore edition 


\begin{tabular}{llllll}
\hline Peshawar & & & Lahore & & \\
Variables & F & $\%$ & Variables & F & \% \\
Yes & 2 & 5.1 & Yes & 9 & 23.7 \\
No & 37 & 94.9 & No & 29 & 76.3 \\
Total & 39 & 100.0 & Total & 38 & 100.0 \\
\hline
\end{tabular}

Regarding pictorial representation table 5 shows that in $94.9 \%$ stories were published without picture while in Lahore edition published $76.3 \%$ news without pictorial representation. It is also shows that Peshawar edition pasteurized the stories only $5.1 \%$, while Lahore edition $23.7 \%$.

Table 6. Comparison of news stories according to kinds of women rights violation in daily express Peshawar \& Lahore edition

\begin{tabular}{|c|c|c|c|c|c|}
\hline Peshawar & & & Lahore & & \\
\hline Variables & $\mathbf{F}$ & $\%$ & Variables & $\mathbf{F}$ & $\%$ \\
\hline Firing & 1 & 2.6 & Firing & 1 & 2.6 \\
\hline Firing/killing & 2 & 5.1 & Abuse/killing & 1 & 2.6 \\
\hline Harassment/kill & 1 & 2.6 & Harassment & 5 & 13.2 \\
\hline Honor killing & 8 & 20.5 & Honor killing & 1 & 2.6 \\
\hline Kidnapping & 2 & 5.1 & Kidnapping & 4 & 10.5 \\
\hline Kidnapping/kill & 1 & 2.6 & Kidnapping/kill & 1 & 2.6 \\
\hline Killing & 15 & 38.5 & Killing & 12 & 31.6 \\
\hline Protest & 2 & 5.1 & Protest & 1 & 2.6 \\
\hline Suicide & 5 & 12.8 & Suicide & 4 & 10.5 \\
\hline Attack & 2 & 5.1 & Suicide attempt & 1 & 2.6 \\
\hline ------------- & ------------------ & ------------------ & Rape & 4 & 10.5 \\
\hline ---------- & ------------------- & ------------------- & Rape/killing & 1 & 2.6 \\
\hline --------- & ---------------- & ------------------ & Teasing/torture & 1 & 2.6 \\
\hline Total & 39 & 100.0 & Total & 38 & 100.0 \\
\hline
\end{tabular}

Table 6 demonstrates the kind of violation of women rights news stories that Peshawar edition covered news regarding firing $2.6 \%$, firing then killing $5.1 \%$, harassment then $2.6 \%$, honor killing $20.5 \%$, kidnapping $5.1 \%$, kidnapping then killing $2.6 \%$, killing $38.5 \%$, protest for women rights $5.1 \%$, suicide cases $12.8 \%$ and attacks new stories $5.1 \%$. The table also shows the ratio of Punjab community that Lahore edition published 2.6\% regarding finding issues, $2.6 \%$ about abuse then killing, $13.2 \%$ regarding harassment, $2.6 \%$ about honor killing, $10.5 \%$ about kidnapping, $2.6 \%$ on the subject of kidnapping then killing, $31.6 \%$ concerning killing, $2.6 \%$ protest for women rights, $10.5 \%$ on the topic of suicide, $2.6 \%$ on suicide attempts, $10.5 \%$ on the subject of rape cases, $2.6 \%$ about rape then killing cases and $2.6 \%$ concerning teasing and torture issues.

\section{Hypotheses support}

The results of the study denied that first hypothesis that "Violation of women rights is greater in Punjab community than the Pashtuns" that $50.6 \%$ stories have been published by Peshawar edition, while $49.4 \%$ by Lahore edition regarding women rights violation. It also confirmed daily express newspaper has been covered more women rights violation news of the Pashton community as compare to the Punjab community. According to the population ratio Pashtun violated more women rights then Punjab community, because Pashtuns ratio is low than Punjabis in Pakistan.

The outcome of the research also denied the second hypothesis "Coverage of women related crime issues is more in Peshawar edition than Lahore edition" that Peshawar edition covered more stories than 
Lahore edition as $50.6 \%$ stories have been published by Peshawar edition, while $49.4 \%$ by Lahore edition regarding women rights violation. It is concluded that Peshawar edition given more coverage to women rights violation than Lahore edition

The third hypothesis "Peshawar edition is more ethical in covering issues of violation against women" has been proved that $94.9 \%$ news stories have followed journalistic ethics, while only $5.1 \%$ unethically reported by Peshawar edition. On the other hand Lahore based reporters followed $94.7 \%$ ethical standards, while 5.3\% stories were filed unethically. It is shows that Peshawar based reporters followed ethics more than Lahore base reporters during filing stories regarding women rights violation.

As Hypothesis in four "Lahore edition newspaper gives more importance to issues related to violation of women rights" has been also confirmed that Peshawar edition covered news regarding firing $2.6 \%$, firing then killing $5.1 \%$, harassment then $2.6 \%$, honor killing $20.5 \%$, kidnapping $5.1 \%$, kidnapping then killing $2.6 \%$, killing $38.5 \%$, protest for women rights $5.1 \%$, suicide cases $12.8 \%$ and attacks new stories $5.1 \%$. The table also shows the ratio of Punjab community that Lahore edition published $2.6 \%$ regarding finding issues, $2.6 \%$ about abuse then killing, $13.2 \%$ regarding harassment, $2.6 \%$ about honor killing, $10.5 \%$ about kidnapping, $2.6 \%$ on the subject of kidnapping then killing, $31.6 \%$ concerning killing, $2.6 \%$ protest for women rights, $10.5 \%$ on the topic of suicide, $2.6 \%$ on suicide attempts, $10.5 \%$ on the subject of rape cases, $2.6 \%$ about rape then killing cases and $2.6 \%$ concerning teasing and torture issues.

\section{Discussion}

Lewis, Pual M. (2009) said that Pakstuns are living in Pakistan and Afghanistan history known as Afghans and Pathans. This is basically an ethnic groups living in both the cross border of Pakistan and Afghanistan. The mother language of the community is Pashto or Pukhto and the code of conduct for their lives is called Pukhtuwali, which is both for the individual and community.

Roy, Kaushik. (1988) said that in term of land area Punjab is second largest province of Pakistan. It is also a fertile region of the country. The people of area are very hardworking as well as hospitable due to rich culture.

Punjab - the land of five rivers - lies in North West India. In the Vedic Era, Punjab was called 'Sapat Sindu'. Sapat Sindu means the land of seven rivers - the Sindu, Jehlum, Ravi, Chenab, Beas, Satluj and Yamuna. The Mughals personalized its name by calling it 'Panj - Aab' or -the land of five riversexcluding Sindhu and Yamuna. Punj means five and aab means water, so Punjab means -the land of five rivers. Grey, C. (1993) said that the local and native language of the area is called Punjabi, but in the southern Punjab the people speaks sriaki. They are also using other languages such as Urdu and some other languages. Majority of the population are the followers of Islamic religion, while some of the areas are Shia, Christian and Hindus followers.

Haider.M (February 19, 2014) reported that Pashtuns women are more suffer from human right violation as compare to the rest of the country. "One in 10 rural women in KPK and Balochistan each routinely experienced domestic physical violence compared to only 5 per cent rural women in Punjab and 1.5 per cent rural women in Sindh."

Gender is non-traditional security threat to security of Pakistan. Women in Pakistan are half of the population but they are performing secondary role in the country. They are facing domestic violence, physical hardship, educational discriminations, work place harassment etc. in the country. Honor killing, Karo Kari, Swara, Vani, acid throwing, forced mirage, etc. are the problems are facing women in Pakistan (Iqbal, Afzal, \& Inayat, (2012). 
In Pakistan, females are suffering from cultural and social standards. They are facing not only facing domestic problems but also financial, transportation, narrow minded set, lack of family support, higher education and harassment (Bukhari et al. 2018).

\section{Conclusion}

After the data analysis it has been inferred that that most of the objective and hypotheses of the study have been proved by the data collected from the selected editions of the daily express newspaper. It is concluded that both the editions of the daily Express covered the women rights violation issues. It is summarized that women rights violation is beg issue of the country.

On the base of the results it is also summarized that Peshawar edition has given more coverage on the front, city and back pages to women rights violation. It is concluded due to the more coverage wariness level would be increased in the Pashtun society regarding the issue.

It is also sum up on the base of the outcome of the study that the Lahore edition of the Express Newspaper has not ethically covered women rights violation news, while Peshawar edition were covered more ethically the issue. It is concluded that Peshawar based journalists are following cultural values of the Pashtun Society so for that the issue has been covered positively.

It summarized that Peshawar edition has given more coverage than Lahore edition to women rights violation news. According to the population ratio Pashtun violated more women rights then Punjab community.

Due to the results of the study it is concluded that Pashtuns violated the women rights through 10 different practices in which mostly they have done were honor killing, killing and suicide. While Punjabis' cross the limitations of the women rights by 13 various tactics in which they mostly applied Harassment, kidnapping, killing and rape. It is inferred that Punjabis' are more violent than Pashtun in the context of the women rights violation.

\section{References}

Bukhari, A.H.S., Gaho, G.M. and Soomro, K.H. (2018) Gender Inequality Problems \& Its Solutions in Pakistan. Research Journal of Political Science, 7, 47-58.

Haider.M (February 19, 2014), The continued abuse of the Pashtun woman, retrieved fromhttps://www.dawn.com/news/1088086

Iqbal, H., Afzal, S., \& Inayat, M. (2012). Gender Discrimination: Implications for Pakistan Security. IOSR Journal of Humanities and Social Science, 1(4), 16-25.

Jawad Syed (2008) "The representation of cultural diversity in Urdu-language newspapers in Pakistan: A study of Jang and Nawaiwaqt", South Asia: Journal of South Asian Studies, Rutledge, Taylor \& Francis Group of Publications, Vol.31, No. 2, pp. 317-347.

Mubarak, M., Rana, A. M. K., Khan, M. M. A., Mujahid, A. B., \& Chawla, M. I. (2020). Rethinking of women empowerment in Pakistan; Dimensions and Trends related to female in District Rawalpindi. Pakistan Vision, 21(1), 1. 
Naylor, B. (2001). "Reporting violence in the British print media: gendered stories" Howard Journal of Criminal Justice, 40(2), 180-94

Roy, Kaushik.(1988) India's Historic Battles: From Alexander the Great to Kargil. Permanent Black, India. pp. $80-1$

Ruben David. H (1995) John Searle's The Construction of Social Reality", Journal of Philosophy and Phenomenology Research, Vol. 57, No. 2, pp 443-447.

Ruben David. H (1995) John Searle's The Construction of Social Reality", Journal of Philosophy and Phenomenology Research, Vol. 57, No. 2, pp 443-447.

Sabiha Shaheen (2005), "Street Harassment against Girls in District Gujranwala”, Sharhrah-e-Quaid-iAzam Rahwali, Gujranwala, PP42-43

Shoemaker, P. J., \& Reese, S. D. (1996). Mediating the message ( $2^{\text {nd }}$ ed). White Plains, NY: Longman.

Silverstein, B., \& Flamenbaum, C. (1989). Biases in the perception and cognition of the actions of enemies. Journal of Social Issues, 45, 2, 33-51.

Taimur-Ul Hasan (2012) “Towards a More Responsible Press”, AUDC, Volume 6, No 2, 2012, 3152, Romania.

|Tasneem Ahmar (2001), “A National Study on Monitoring and Sensitization of Print Media on the Portrayal of Women", Islamabad, Uks-A Research, Resource and Publication Centre Women and Media.

Wimmer \& Dominic (2011), Mass Media Research, USA, wads worth. P9. 